\title{
Narrativas de leitoras da revista Capricho: \\ memória e subjetividade (1950 a 1960)*
}

\author{
Raquel de Barros Pinto Miguel** \\ Joana Maria Pedro***
}

\section{Resumo}

Este trabalho tem como objetivo apresentar a possibilidade de uma revista, destinada ao público feminino, servir como "lugar de memória" (Pierre Nora). Para tanto, formou-se um grupo com três leitoras da revista Capricho (1950 a 1960), onde elas puderam folhear exemplares da revista da época citada. Esse método proporcionou vislumbrar uma forma de acesso, através das revistas, memórias e narrativas, a aspectos relacionados à história das mulheres e das relações de gênero. Nessa experiência, a publicidade ficou evidenciada como importante "lugar de memória", possibilitando reflexões acerca da participação das propagandas na constituição das subjetividades das mulheres $e$ dos homens de uma geração. As diversas lembranças trazidas pelas leitoras evidenciaram a diversidade de possibilidades na constituição das subjetividades, mesmo que em uma mesma época.

Palauras-chave: Gênero, Revista Feminina, Memória, Subjetividade.

\footnotetext{
" Recebido para publicação em abril de 2008, aceito em março de 2009.

** Doutora em Ciências Humanas, professora do Departamento de Psicologia, Universidade Federal de Santa Catarina. raquelbarros@hotmail.com

**** Professora do Programa de Pós-graduação em História, Universidade Federal de Santa Catarina. joanamaria.pedro@gmail.com
} 
Narratives of Readers of the Magazine Capricho:

Memory and Subjectivity (1950 and 1960)

\begin{abstract}
This paper aims to present the possibility of a magazine, for the female public, serving as a "place of memory" (Pierre Nora). In order to do this, a group was formed with three female readers of the magazine Capricho (1950 to 1960), where they could browse magazine copies of the mentioned time. This method provided a glimpse of an access, through the journals, memoirs and narratives, to the aspects related to the history of women and of gender relations. Through this experience advertising was shown as an important "place of memory", enabling reflection on the participation of advertisements in the constitution of subjectivities of women and men of a generation. The memories brought by several readers pointed to the diversity of possibilities in the constitution of subjectivities, even within the same season.
\end{abstract}

Key Words: Gender, Women's Magazine, Memory, Subjectivity. 
O passado é uma invenção do presente. Por isso é tão bonito sempre, ainda quando foi uma lástima... A memória tem uma bela caixa de lápis de cor.

Mário Quintana

Ao folhearem exemplares da revista Capricho de 1950 e 1960, três mulheres ${ }^{1}$, que foram leitoras desta revista na época, surpreendem-se ao se depararem com um anúncio de produtos Cashemere Bouquet.

Ir- Gente! Como eu me lembro disso! Olha aqui, ó, Cashmere Bouquet.

[Diante de tal propaganda, Lídia se recorda de um episódio vivido por ela, sua prima (Vani) e seu primo (Felipe)]

L- Ai, nem fala! Eu e a Vani usávamos Cashmere Bouquet, aí o Felipe [primo de Lídia, irmão de Irene e Vani] entrou no banheiro um dia, e nós assim "empoada" para sair [gesticula como se estivesse passando pó no rosto], aí ele [faz com o nariz como alguém que está cheirando algo]: Cashmere Bouquet!!! Meu Deus do céu!!! [L. o imita colocando as mãos no rosto, tampando os olhos]. Isso é puta que usa!!!

Irene ri diante do relato de Lídia e Izaura, por sua vez, também se declara consumidora destes produtos. Lídia salienta que ela e a prima jogaram fora tudo que tinham desta linha de cosméticos. Já Irene fez questão de frisar que não utilizava esses produtos, referindo-se especialmente ao pó de arroz: "Ir - Eu não usava, porque eu não usava essas coisas, mas elas [Lídia e Vani]

\footnotetext{
1 Irene (Ir -58 anos, viúva), Izaura (Iz -61 anos, separada) e Lídia (L -69 anos, solteira), todas leitoras da revista Capricho entre as décadas de 1950 e 1960. Estas mulheres foram entrevistadas por Raquel como parte da pesquisa realizada em seu doutorado no Programa de Doutorado Interdisciplinar em Ciências Humanas, sob o título: "A revista Capricho como lugar de memória", onde contou com a orientação da Profa. Dra. Joana Maria Pedro e co-orientação da Profa. Dra. Carmen Rial.
} 
usavam".

Anúncios de produtos Cashemere Bouquet tinham "cadeira cativa" nas páginas de edições da Capricho dos anos de 1950 e 1960, dividindo o espaço publicitário com outros ítens - fermento em pó Royal, Anti-sardina, creme C Ponds, Sonrisal, Melhoral, soutien Darling, Leite de Colônia e Leite de Rosas, Maisena, Gessy Léver, desodorante, Leite moça, Modess, sardinhas Coqueiro e utilidades domésticas (panelas, enceradeira, batedeira).

A revista Capricho, certamente, era uma mídia bastante atraente para os anunciantes, especialmente por ter vivido, entre estas décadas, seu período de apogeu, estampando em suas capas os dizeres: "A maior revista feminina da América do Sul".

Capricho foi criada em $1952 .^{2}$ Seu conteúdo era constituído de fotonovelas, dirigidas a um público mais adulto. Ainda nesse ano, a revista foi ampliada e passou a abordar os seguintes temas: moda, beleza, comportamento, contos e variedades; contemplando assuntos como: técnicas de conquista, namoro e virgindade. Em 1956, a Capricho atingiu a, até então, maior tiragem de uma revista da América Latina, rompendo a marca dos quinhentos mil exemplares. Esse sucesso perdurou ao longo dos anos 1960 e estava relacionado, especialmente, às fotonovelas por ela publicadas. ${ }^{3}$

A Capricho existe até os dias atuais e continua sendo uma revista de destaque entre as adolescentes. Claro que para manterse no mercado ao longo de tantos anos, perpassando diferentes gerações, ela precisou passar por diversas reformulações: da "revista da moça moderna" para a "revista da gatinha", readequando seu conteúdo a seu público-alvo, exercício realizado constantemente pela revista.

2 As informações deste breve histórico sobre a Revista Capricho foram cedidas, em abril de 2003, via e-mail, por Simone Miranda, responsável pelo serviço de atendimento ao leitor desta revista.

${ }^{3}$ Vale ressaltar que as fotonovelas foram publicadas nas páginas da revista Capricho até 1982. 
Tendo em mente a idéia da revista Capricho como colaboradora na constituição de subjetividades, nos utilizaremos dela, aqui, como um lugar de memória (Nora, 1993). Dessa forma, através das narrativas de leitoras da revista, das lembranças e memórias suscitadas ao virar as páginas da Capricho, buscamos ter acesso a aspectos relacionados à constituição delas como mulheres, à história das mulheres, ao lugar da sexualidade feminina $e$ às relações de gênero.

Os relatos de Irene, Izaura e Lídia foram coletados através de uma entrevista realizada em grupo com estas três mulheres. ${ }^{4}$ Optamos pela realização de entrevista em grupo com o intuito de proporcionar uma discussão entre as mulheres que facilitasse, assim, o surgimento de lembranças. ${ }^{5}$

Uma vez que tomamos a revista Capricho como um lugar de memória, no encontro com este grupo levei oito exemplares originais da revista datados de 1950 e 1960. A utilização das revistas, tomadas como lugares de memória, vem com o intuito de incrementar a discussão em grupo, suscitando, de maneira mais eficaz, as recordações das leitoras, buscando atingir o modo como se constituíram as subjetividades de mulheres de uma época. Ao longo da entrevista, as leitoras puderam manipular livremente as revistas disponibilizadas.

A fim de obter os depoimentos das três mulheres leitoras da Capricho, lançamos mão da fonte oral como recurso metodológico. O interesse da história pela oralidade, nos dias atuais, está atrelado ao reconhecimento de que sua utilização possibilitaria o aceso a informações, até então, não consideradas, viabilizando novas possibilidades de análises históricas.

\footnotetext{
4 A entrevista em grupo aconteceu dia 22 de janeiro de 2006, na casa de Irene, mais especificamente em seu quarto. Posicionamo-nos ao redor de sua cama: as três entrevistadas sentadas em cadeiras, uma ao lado da outra e Raquel (pesquisadora), do outro lado da cama, ajoelhada no chão.

5 Esse encontro foi filmado. Tal técnica foi escolhida por compreendê-la como sendo a mais apropriada, por reproduzir com maior riqueza de detalhes a entrevista realizada em grupo.
} 
Entretanto, apesar do aumento de interesse por essa área, a fonte oral é alvo de ataques e críticas, devido a algumas peculiaridades a ela inerentes, especialmente no que concerne à sua íntima relação com a subjetividade.

Porém, é justamente o caráter subjetivo das fontes orais, ou seja, das pessoas, um dos seus pontos de maior riqueza, de maior força. Os críticos dessa metodologia, por sua falta de "objetividade", se esquecem que os documentos escritos, na maior parte das vezes, foram elaborados com base em fontes orais. ${ }^{6}$ Assim, é possível questionar o que seria, então, objetivo e verdadeiro?

Diante da existência inquestionável da subjetividade, o que se deve fazer no trabalho com fonte oral é procurar uma maneira de lidar com ela, compreendê-la e utilizá-la. Para tanto, é importante ter em mente que o conteúdo das narrativas das pessoas entrevistadas constitui uma visão dos fatos, uma das versões possíveis.

Nesse sentido, Portelli afirma:

Não temos, pois, a certeza do fato, mas apenas a certeza do texto. O que nossas fontes dizem pode não haver sucedido verdadeiramente, mas está contado como verdadeiro (Portelli, 1996:64). [E ainda mais] (...) muito aconteceu na mente das pessoas, em termos de sentimentos, emoções, crenças, interpretações - e, por esse motivo, até mesmo erros, invenções e mentiras constituem, à sua maneira, áreas onde se encontra a verdade (Portelli, 1997:25).

Uma vez que a fonte oral lida com "elementos mutáveis" subjetividade, memória, discurso e o diálogo-, ela encontra-se aberta a um horizonte de possibilidades, sejam reais ou imaginárias. Uma história contada por um indivíduo singular é, nessa visão, representativa deste universo de possibilidades. E ela

${ }^{6}$ Paul Veyne (1987) discute o fato de os historiadores clássicos da Grécia basearem suas narrativas em relatos de seus contemporâneos. 
é representativa não por ser "normal", ou por estar dentro da média; mas por ser única. Dessa forma, a subjetividade de quem está a narrar um fato pode ajudar a desenhar uma subjetividade mais ampla.

Assim, é possível refletir que cada uma das três mulheres entrevistadas apresenta histórias que são representativas de uma época. Cada uma delas apresenta singularidades que acabam por construir um grande mosaico de possibilidades $e$ de subjetividades. Mostram que mesmo tendo vivido sua juventude em uma mesma época, esta serviu como cenário, ou melhor, cenários, para a constituição de diversas subjetividades.

Cabe ressaltar que partimos da idéia de que a subjetividade é constituída através das relações sociais, sendo estas mediadas pela linguagem e cultura, reconhecendo o sujeito como ativo $e$ histórico. Dessa forma, a subjetividade não tem uma essência, nem uma forma definida, é sim uma produção assumida e vivida pelo indivíduo em suas existências particulares a partir de uma construção social sempre inacabada (Guattari, Rolnik, 1986). Assim,

Podemos pensar que ela se assemelha a uma duna de areia que se movimenta e se deixa esculpir pelo sopro dos ventos. Escultura mutante no/do tempo, que se realiza no jogo interminável de construção/ desconstrução. Como não é dada aos homens pela natureza se constrói no campo social e histórico (Lanzarin, 2000:30).

Subjetividade e gênero apresentam-se, ao longo deste texto, como categorias que se entrelaçam. Podemos até mesmo falar que trataremos, aqui, de "subjetividades generificadas". Nesse sentido, Siqueira (1997) afirma que gênero pode ser visto como componente/compositor da subjetividade. Dessa forma, mulheres $e$ homens constituem suas subjetividades tendo gênero como parte importante e constitutiva destas.

O diálogo apresentado no início deste texto mostra a existência de um mosaico de possibilidades e subjetividades. As 
narrativas ali relatadas abrem um leque de discussões. Esse exemplo é representativo, especialmente, do processo de constituição de subjetividade onde a categoria classe social ganha destaque. Era importante que "moças de família" se diferenciassem das "putas e pobres". O que fica evidenciado na fala de Lídia quando ela diz: "jogamos tudo fora".

Nesse diálogo, fica clara a presença de relações de gênero $e$ classe. Entre elas, pode-se destacar o fato de ter sido um homem quem as repreendeu por usarem produtos Cashemere Buquet. Não é por acaso que ao descrever a moral dos anos 1950, Bassanezi (2001) comenta que

o código da moralidade era de domínio geral $e$ praticamente todos se sentiam aptos a julgar os comportamentos de uma jovem: os pais, os vizinhos, os amigos e amigas, os educadores, os jornalistas... (Bassanezi, 2001:613).

Entretanto, a mulher encontra como algozes não apenas homens, mas também as próprias mulheres. Neste exemplo, Irene faz questão de diferenciar-se das demais, afirmando não usar os produtos daquela marca. Sua fala demonstra desprezo àqueles produtos, ao referir-se a eles como "essas coisas". A reação de Lídia e Vani diante do comentário de Felipe: "isso é puta que usa!!!", evidencia o quanto as relações de gênero se dão tanto entre mulheres e mulheres, quanto entre homens e mulheres, relações estas permeadas pela imbricação existente entre $\mathrm{o}$ individual e o coletivo.

O diálogo evidencia presença de diferentes histórias, diferentes memórias suscitadas por um mesmo anúncio. Sendo cada uma destas histórias representativa de uma época, representando uma das inúmeras possibilidades disponibilizadas por um determinado momento vivido em um determinado contexto. 


\section{História das mulheres}

Subjetividades, pluralidades, possibilidades, múltiplas vozes $e$ interpretações são conceitos caros não apenas às fontes orais, mas também à história das mulheres. Esta história surge como um novo campo de conhecimento, visando escrever uma história que incluísse as mulheres - uma história que questione as "verdades" sedimentadas, contribuindo para uma existência menos excludente.

Cabe, inicialmente, abordar uma discussão que encontra espaço entre pessoas envolvidas no estudo da história das mulheres, referente ao próprio termo "história das mulheres". Joan Scott (1995), por exemplo, questionou a eficácia dessa terminologia, argumentando que seu uso poderia ser limitador. Seria como se a história das mulheres tomasse um aspecto de uma história à margem da história tradicional, conferindo-lhe, assim, um status inferior. Como se dissesse respeito apenas à vida privada, mais especificamente ao sexo e à família, devendo, portanto, manter-se separada da história política e econômica. Como alternativa para tal impasse, Scott sugere a inserção do termo "gênero" como uma categoria de análise. Este termo, para a autora, conferiria maior credibilidade e erudição aos estudos, devido sua conotação mais neutra quando comparado a "mulheres". Da mesma forma, um forte aspecto que vem atrelado à denominação "gênero" é o fato de ele dizer respeito não apenas às mulheres, mas sim às relações sociais de sexo.

Mais do que uma simples troca de termos, o importante é manter a visão de que estudos sobre mulheres não possuem a intenção de substituir o sujeito masculino pelo feminino. Muito menos se trata de querer incluir as mulheres em uma narrativa histórica já existente. O objetivo é manter um diálogo com a história enquanto disciplina, considerando

(...) que a constituição do masculino e do feminino enquanto identidades de gênero é uma construção histórica 
que só ganha realidade se mostrada dentro de um sistema de relações que implicam dominação, tensão, resistência. Qualquer informação sobre a questão das mulheres implica necessariamente em informações sobre o homem (Maluf, 1995:34).

Uma questão é fato: o pouco espaço ocupado pelas mulheres nas narrativas da história tradicional. Pesquisas sobre as mulheres precisaram se valer das mais diversas fontes para atingir seus objetivos. Essa busca por fontes de informação acabou por favorecer a interface entre a utilização de fontes orais e história das mulheres. A história das mulheres encontra na fonte oral um campo fértil para suas investigações. Haja vista que, já em 1977, no periódico feminista estadunidense Frontiers: a journal of women, um dos mais antigos no ramo, foi publicado um número especial sobre a história oral de mulheres, onde Sherna Berger Gluck (apud Salvatici, 2005:30) proferiu o seguinte:

Recusando-se a serem deixadas historicamente sem voz por mais tempo, as mulheres estão criando uma nova história usando nossas próprias vozes e experiências. Estamos contestando o conceito tradicional de história, aquilo que é "historicamente importante", e estamos afirmando que nossa vida cotidiana é história. Usando uma tradição oral, tão antiga quanto a memória humana, estamos reconstruindo nosso próprio passado.

A aliança entre fontes orais e história das mulheres aumentou o campo de possibilidades no que concerne às pesquisas históricas, favorecendo o interesse em assuntos comuns, até então marginalizados, como as atividades domésticas, a vida privada, o cotidiano $e$ as mulheres de carne e osso. A utilização de fontes orais contribui na medida em que ela fornece subsídios teóricos e metodológicos aos estudos sobre as mulheres. "Evocando a subjetividade do privado, a história oral ajudou a 
restituir-lhe a dimensão política, dando significação política aos discursos pessoais das mulheres" (Del Priore, 1998:229).

A complexidade da história das mulheres é tamanha, que se torna inviável gravitar em torno apenas das questões relacionadas a gênero. Aspectos como classe, geração, religião e etnia ganham peso e obrigatoriedade em suas discussões. Essa abertura a novos aspectos e possibilidades, certamente, encontra ênfase na interface entre esta história e a história oral.

No que tange à imbricação entre história oral (e, conseqüentemente, memória) e história de mulheres, vale citar a fala de Salvatici, que utiliza, inclusive, o termo "história oral de mulheres".

A história oral de mulheres (...) contribui para enfocar os mecanismos de inclusão e exclusão que regem memórias públicas. [Ela] suscita novas questões na esfera da relação entre história e memória. [Ressaltando] a necessidade de um discurso público capaz de admitir e acolher as narrativas de diferentes sujeitos sociais, a necessidade de um arcabouço público no qual as memórias de todos possam ser reconhecidas e, ao mesmo tempo, elas próprias possam se reconhecer. A história oral de mulheres tem destacado a urgência do processo de "democratização da memória", que é a condição básica para as democracias contemporâneas (Salvatici, 2005:40).

Imaginamos que este trabalho, onde tomamos a Capricho como um dispositivo de constituição de subjetividades e como lugar de memória, visando ter acesso à forma como mulheres constituíram suas subjetividades através da revista, possa contribuir para a "democratização da memória".

\section{E por falar em memória...}

Se as fontes orais abrem um horizonte de possibilidades, delineando diferentes perspectivas da realidade, com a memória 
não poderia ser diferente. E é justamente essa pluralidade da memória que faz com que estudos e autores que a ela se dedicam a enfoquem das mais variadas maneiras.

Pode-se citar, por exemplo, as discussões a respeito das diferenças entre memória voluntária e involuntária (presente em Walter Benjamin e Marcel Proust), ou ainda aquelas referentes à memória coletiva e memória individual (como em Maurice Halbwachs e Jacques Le Goff).

Para Proust, a memória voluntária, que não vai além da memória dos fatos, é superficial, repetição mecânica, memória intelectual, ou seja, uma memória menor, chegando a ser um obstáculo à verdadeira memória. Ela exclui a dimensão afetiva $e$ descontínua da vida. Em oposição a esta memória, Proust traz a memória involuntária: a verdadeira, mais elevada, espontânea, fugidia, feita de imagens que aparecem e desaparecem como lampejos, sendo, então, instável e descontínua. De acordo com Proust, essa memória tem o poder de "fazer reencontrar os dias antigos, o tempo perdido, face aos quais os esforços de minha memória e de minha inteligência sempre fracassavam" (apud Seixas, 2004:43).

Benjamin, entretanto, diverge de Proust quanto à ênfase, desferida por este, ao indivíduo isolado no que se refere à memória involuntária, assim como o valor exclusivo atribuído pelo escritor a este tipo de memória. O primeiro insiste na coexistência dos componentes tanto individuais quanto coletivos da memória. Para ele, a memória, mesmo individual e involuntária, preserva relações com o mundo coletivo:

Onde há experiência no sentido estrito do termo, entram em conjunção, na memória, certos conteúdos do passado individual com outros do passado coletivo. Os cultos, com seus cerimoniais, suas festas (...) produziram reiteradamente a fusão desses dois elementos da memória. (...) As recordações voluntárias e involuntárias perdem, assim, sua exclusividade recíproca (Benjamin, 1995:107). 
Dessa forma, pontos de contato podem ser estabelecidos entre o pensamento de Benjamin e o do sociólogo Maurice Halbwachs (2004), apesar deste último, ao contrário de Proust, centrar sua discussão em torno da memória coletiva. Para Halbwachs, é o coletivo quem consolida a memória, destacando, outrossim, o vínculo entre as relações que estabelecemos $e$ mantemos com grupos e a importância destes como auxiliares no ato de lembrar.

Portelli, por sua vez, critica o uso do termo "memória coletiva", argumentando:

A memória é um processo individual, que ocorre em um meio social dinâmico, valendo-se de instrumentos socialmente criados e compartilhados. Em vista disso, as recordações podem ser semelhantes, contraditórias ou sobrepostas. Porém, em hipótese alguma, as lembranças de duas pessoas são (...) exatamente iguais (Portelli, 1997:28).

Cabe, entretanto, ressaltar que, no caso de Halbwachs, talvez seu uso do termo "memória coletiva" possa se aproximar da visão de Portelli, na medida em que o primeiro não exclui a memória individual. Para Halbwachs (2004:55),

cada memória individual é um ponto de vista sobre a memória coletiva, este ponto de vista muda conforme o lugar que ali eu ocupo, este lugar mesmo muda segundo as relações que mantenho com outros meios.

Seja com Portelli, enfatizando a ação, a subjetividade do indivíduo, seja com Halbwachs, destacando a coletividade, o que interessa é destacar que a memória envolve o coletivo e o individual. $\mathrm{O}$ que não poderia ser diferente, uma vez que $\mathrm{O}$ subjetivo é vivenciado no coletivo: "(...) é a marca pessoal que retira significados particulares de uma coleção de imagens comuns" (Maluf, 1997:37).

A experiência vivenciada com a realização do grupo de 
mulheres leitoras da Capricho corrobora essa relação entre o individual e o coletivo em se tratando de memória. Através das narrativas das entrevistadas, foi possível verificar o diálogo entre a memória involuntária, destacada por Proust, a memória coletiva de Halbwachs. Em diversos momentos, ao longo da entrevista, a memória espontânea, fugidia, instável e descontínua, que faz reencontrar os dias antigos, foi suscitada pelo coletivo, seja pela revista, seja através do diálogo de memórias entre essas mulheres, provocado pelo fato da entrevista ter sido realizada em grupo. $\mathrm{O}$ grupo, as outras mulheres contemporâneas, mesmo que com histórias totalmente diferentes, serviu, como destaca Halbwachs, como auxiliares no ato de lembrar. O que, entretanto, não deixou de guardar as marcas individuais, as subjetividades, as particularidades de cada uma destas mulheres, de cada uma de suas memórias.

O diálogo a seguir, relacionado a uma propaganda de Modess presente na Capricho, ilustra a íntima relação entre memória coletiva e individual, ou seja, as singularidades presentes em um mesmo contexto histórico e social.

Iz - Modess, ó o Modess aqui.

[Após este comentário de Izaura, perguntei a elas se quando ficaram menstruadas tinham conhecimento do que estava acontecendo. Izaura disse que não $e$ já complementou contando que usava toalhinha]

Iz - A minha mãe mandou a vizinha, a irmã do... como é que ele chama... o Íris Rezende, aquele que foi ministro aí. A gente morava em frente. (...) Foi ela quem me falou. Mas pintou um trem, uma coisa tão horrorosa. Que eu não sei o quê que era aquilo. Aí quando veio foi tão simples. O meu foi como uma borra de café. (...) Eu olhei: olha o quê que é isso. Não sabia não. Boba, eu não falei que eu era boba? (...) Aí eu falei com a mamãe, chamei, não lembro se tinha alguém em casa, não sei se era a empregada. Aí ela falou: ô boba, você acabou de ficar moça, menstruada. (...) Eu fiquei com 13. 
[Lídia disse que quando menstruou sabia o que estava acontecendo. Irene contou que também sabia porque se informava]

Ir - Não que a mãe me falasse. (...) Eu escutava as gurias falando, no colégio elas comentavam. E eu fiquei muito tarde, né Raquel. Eu fiquei com 15 anos. E aí fiquei e fui pro banheiro do colégio. Aí a Cristina, eu me lembro como se fosse hoje. A Cristina foi e eu disse: "Cristina, eu fiquei mocinha, mas não conta pra ninguém". Aí ela saiu de lá do banheiro, o banheiro do colégio era enorme, né. Saiu berrando: "A Irene ficou mocinha! A Irene ficou!" Ai, foi um escândalo! Eu disse: "sua desgraçada!"

[Irene e Lídia contaram que naquela época não tinha Modess, mas sim paninho. Usavam toalhinhas que eram lavadas e quaradas ${ }^{7}$. Então eu questionei, pois como a própria propaganda indicava os absorventes já existiam. A este questionamento Izaura respondeu]

Iz - É, mas é porque decerto era para quem tinha dinheiro.

Nós éramos pobres [riu]

[Irene ainda insistiu em sua teoria de que os absorventes não existiam em sua juventude. $\mathrm{O}$ que a faz persistir nesta idéia é a lembrança de Maria, uma amiga rica que quando foi para o internato tinha, em seu enxoval, essas toalhinhas bordadas]

Ir - Ela era uma menina rica, ela podia comprar.

[Comentei o quanto devia ser desconfortável usar essas toalhinhas, principalmente se estivesse usando calça comprida. Izaura rebateu dizendo que não usava calça, que só foi usá-la quando ficou mais velha].

Essas narrativas, suscitadas pelo anúncio de Modess, mostram diferentes subjetividades em um mesmo contexto. Mulheres de uma mesma geração, pertencentes a uma mesma classe social, leitoras de uma mesma revista, sendo, inclusive, duas delas (Lídia e Irene) primas; e ao mesmo tempo com experiências únicas e particulares. As três, que já haviam se deparado com a

${ }^{7}$ Quarar uma roupa é o mesmo que branqueá-la, expondo-a ao sol. 
propaganda deste absorvente em sua juventude, lembraram $e$ teceram comentários. Uma mesma imagem provocou diferentes lembranças: o uso da toalhinha, a mãe omissa quanto ao assunto, a vizinha que explicou de maneira desastrosa o que era menstruação, ter "ficado mocinha" no banheiro do colégio, a toalhinha bordada da menina rica...

Cabe ressaltar o fato de que essas lembranças foram, em parte, provocadas pela pesquisadora que fez a entrevista. As três entrevistadas tinham conhecimento do tema da pesquisa em questão, do que despertaria o nosso interesse. Pode-se conjecturar que se essas mulheres folheassem uma edição da revista Capricho em outro momento, sem ter vinculação com uma pesquisa e sem a presença da pesquisadora, provavelmente não teriam dado essas significações ao verem um anúncio de Modess. Creio que essas leitoras criaram um significado que não teriam criado em outra circunstância.

Outro ponto merece ser ressaltado no que tange à memória: a relação entre passado e presente. A memória consiste em uma versão do passado construída, uma forma encontrada pela pessoa, para viver em paz com seu presente (Portelli, 1997). Lembrar, dessa forma, não é a tentativa de reviver o passado tal como ele foi, mas sim uma reconstrução guiada pela vida que se vive no presente (Bosi, 1987). Ou ainda: "a memória é um fenômeno sempre atual, um elo vivido no eterno presente" (Nora 1993:9).

Assim como as narrativas orais - afinal, ambas se misturam, pois ao narrar, o ato de lembrar encontra-se presente - as memórias abrem um campo de possibilidades compartilhadas, compreendendo um espaço de criação de significações. Nesse movimento, a memória é aberta, englobando a memória e o esquecimento. Dessa forma, os acontecimentos do passado não estão simplesmente "estocados", a espera de uma ordem para virem à tona. Lembramos apenas o que é importante em determinado momento, e isso é histórico. Ou seja, 
A memória age "tecendo" fios entre os seres, os lugares, os acontecimentos, mais do que recuperando-os, resgatandoos ou descrevendo-os como "realmente" aconteceram. Atualizando os passados (...) a memória recria o real; nesse sentido, é a própria realidade que se forma na ( $e$ pela) memória. O tempo perdido e reencontrado (no sentido de retomado, de um tempo que começa de novo, e não do eterno retorno ao mesmo) não se refere apenas ao passado, mas também ao futuro (Seixas, 2004:51).

Conforme dito anteriormente, é possível pensar que a memória apresenta-se como importante fonte quando o objetivo está voltado à discussão acerca das histórias das mulheres. Perrot (2005), referindo-se ao século XIX, nos conta o quanto a memória das mulheres (ou a memória feminina, como ela utiliza em seu texto) estava associada ao privado, à família, ao lar. Vistas como inferiores, menos importantes (tal e qual as próprias mulheres), essas memórias eram consideradas semi-oficiais. Seria como se a memória se encontrasse dividida, obedecendo à divisão tradicional dos papéis sexuais.

As memórias das mulheres estão atreladas a segredos, subterfúgios, silêncios. O pouco que se encontra, especialmente daquelas que viveram no século XIX, está em seus diários íntimos, correspondências familiares, cartas de amor; isso quando esses documentos não foram destruídos, muitas vezes pelas próprias mulheres. "As mulheres freqüentemente apagam de si mesmas as marcas tênues de seus passos neste mundo, como se sua aparição fosse uma ofensa à ordem" (Perrot, 2005:37).

Entre as três mulheres entrevistadas, apenas uma guarda, ainda hoje, registros de sua juventude e estes, inclusive, estão relacionados à revista Capricho. Os contos, presentes nas edições da Capricho de 1950 e 1960, geralmente vinham acompanhados de uma ilustração de acordo com o tema da história, que era, em sua maior parte, o amor. Era comum a figura de um homem $e$ uma mulher se beijando, ou vivendo outras cenas românticas. Irene contou que, além de gostar muito de ler esses contos, tinha 
como hobby reproduzir suas ilustrações: passava o desenho para um papel quadriculado, aumentando-o ou diminuindo-o, guardando-os em pastas. Irene disse ter alguns deles ainda guardados, lembrando-se, especialmente, de uma ilustração que trazia a imagem de uma moça com uma lágrima escorrendo em seu rosto.

Mesmo não sendo anotações pessoais ou confissões de outrora, esses desenhos fazem parte de sua história, de seus hábitos de juventude. Tê-los guardado é uma forma de guardar sua memória, de deixar registrada sua história, de possibilitar que outros tenham acesso a ela.

Seria possível falarmos na presença de especificidades na memória das mulheres? Michelle Perrot responde "não e sim". Não, caso se queira associar essa especificidade a um essencialismo relacionado ao sexo biológico. Sim, se partirmos da idéia de que as relações entre homens e mulheres, entre o masculino e o feminino, são produtos da história. Tendo suas subjetividades constituídas dessa forma, seria possível conjecturar que as memórias das mulheres seguiriam o mesmo trajeto. Portanto, "formada da relação com o tempo e o espaço, a memória, assim como a existência de que ela é o prolongamento, é profundamente sexuada" (Perrot, 2005:43).

$\mathrm{E}$ as memórias dessas leitoras? Seriam elas sexuadas? Seguindo o argumento de Perrot, sim. A começar pelo fato de que o instrumento utilizado como lugar de memória ter sido uma revista destinada ao público do sexo feminino. As memórias foram ativadas ao folhearem páginas recheadas de discursos, imagens $e$ anúncios voltados às mulheres, ou melhor, a uma mulher específica: moça-de-família, noiva, casada ou a procura de um marido, aspirante ao papel de boa esposa e boa mãe. Não é por acaso que, nessa revista nas décadas de 1950 e 1960, predominavam anúncios relacionados à beleza, à higiene e à cozinha (produtos alimentícios e utilidades domésticas). Não sendo por acaso também, o fato dessas três mulheres narrarem memórias ligadas a esses mesmos temas. Diante desse quadro, 
como não falar em memória sexuada? Tanto a revista quanto as memórias são produtos da história, uma história sexuada.

\section{Memórias, silêncios e poderes}

A memória apresenta estreita relação com o poder, com a memória que se deseja manter, com a história oficial que se quer lembrar. Ou seja, com os fatos que "devem", para alguns, ser transmitidos a gerações através dos livros, dos monumentos, das comemorações.

A história das mulheres, em certa medida, é uma história de silêncios. É claro que o silêncio, como salienta Eni Orlandi (1995), não é sinônimo de um vazio de sentidos, de significados; pelo contrário, esse silêncio às vezes pode dizer mais do que o que é dito por uma história escrita por poucos, a serviço dos vencedores.

Walter Benjamin é um dos autores que aparecem para criticar esse historicismo, onde o passado representa uma verdade que não se pode deixar escapar, reivindicando uma história a "contrapelo":

Assim como a cultura não é isenta de barbárie, não o é, tampouco, o processo de transmissão da cultura. Por isso, na medida do possível, o materialista histórico se desvia dela. Considera sua tarefa escovar a história a contrapelo (Benjamin, 1995:225).

Propõe, dessa forma, uma postura que questione a história dos vencedores, atentando-se para a história dos vencidos, para as memórias que não constam nos livros da história oficial. Suas reflexões, certamente, auxiliam na discussão a respeito da história das mulheres.

Jeanne Marie Gagnebin, importante comentadora $e$ conhecedora das obras do autor em questão, afirma que, de acordo com Benjamin, 
A obtenção de uma memória comum, que se transmite através das histórias contadas de geração à geração, é hoje destruída pela rapidez e violência das transformações da sociedade capitalista. Agora, o refúgio da memória é a interioridade do indivíduo, reduzido à sua história privada (Gagnebin, 1999:68).

Assim, caberia ao narrador a transmissão daquilo que a tradição oficial não se recorda, ou não quer recordar, ou seja, "os elementos de sobra do discurso histórico". Ressalta, dessa forma, as dificuldades presentes tanto no processo de narração, quanto na possibilidade de experiências comuns e na atividade de lembrar. Benjamin deixa claro que falar de memória é primordial quando se fala em história a contrapelo.

Pensamos que uma pesquisa que se proponha a desnudar aspectos referentes às histórias das mulheres deve estar atenta a esses "elementos de sobra do discurso histórico", ao que não foi dito, aos silêncios. Nesse sentido, voltar-se ao estudo de papéis tidos socialmente como femininos contribui para a historicização de valores culturais que se têm como fixos e imutáveis.

É muito significativo o fato de as memórias das mulheres encontrarem-se, predominantemente, no âmbito do privado. Por mais que em alguns momentos isso possa ser um entrave para o desenvolvimento de investigações nesta área, devido à escassez de fontes, por outro ângulo isso traz consideráveis revelações a respeito dos modos de vida das mulheres, do lugar social a elas destinado em diferentes épocas.

Perrot destaca, ainda, que além da dificuldade em encontrar fontes que auxiliem no conhecimento das trajetórias das mulheres que viveram em outros momentos, as que existem acabam por contemplar apenas as privilegiadas culturalmente. De tal forma que essas fontes terminam por explicitar as desigualdades sociais de uma época, uma vez que continuam relegando a segundo plano mulheres de camadas sociais mais populares, as iletradas. Se os silêncios são marcantes na história das mulheres, o que dizer 
então destas que além de não serem ouvidas parece que não eram nem vistas. Nesse sentido, cabe a fala de Perrot: "Entre fugacidade dos traços e oceano do esquecimento, os caminhos da memória das mulheres são estreitos" (Perrot, 2005:31).

$\mathrm{O}$ que se pode encontrar acompanhando essas histórias de silêncios, memórias, narrativas? Acreditamos que os jogos de poder formam um fio condutor que perpassa todas essas questões. As discussões sobre o uso de fontes orais, história de mulheres e memória são enriquecidas, e talvez melhor compreendidas, quando se conta com um olhar que contemple essas relações de poder. Seja com Le Goff enfatizando o poder do estado:

A memória coletiva foi posta em jogo de forma importante na luta das forças sociais pelo poder. (...) Os esquecimentos $e$ os silêncios da história são reveladores destes mecanismos de manipulação da memória coletiva. (...) A memória coletiva não é somente uma conquista, é também um instrumento e um objeto de poder (Le Goff, 2003:422, 470).

Seja com Foucault, destacando os micropoderes:

O poder está em toda parte; não porque englobe tudo e sim porque provém de todos os lugares.(...) O poder não é uma instituição e nem uma estrutura, não é uma certa potência de que alguns sejam dotados: é o nome dado a uma situação estratégica complexa numa sociedade determinada (Foucault, 1997:89).

Mesmo alvo de algumas críticas desferidas por feministas, especialmente no que concerne a seu androcentrismo e à sua visão a respeito das identidades sexuais, Foucault fornece importantes "ferramentas" às pesquisas que envolvem a história das mulheres, assim como aos que trabalham com narrativas $e$ memórias.

Algumas contribuições possíveis do pensamento de Foucault à história das mulheres foram elencadas por Perrot (2005). A 
primeira diz respeito à crítica ao essencialismo e ao universalismo, oferecendo, dessa maneira, base teórica para que sejam desconstruídos discursos de cunho essencialista e naturalizante. Da mesma forma, Foucault contribui ao historicizar as relações entre os sexos, encarando-as como construções sociais. O interesse desse autor pelos discursos comuns, pelas escritas "ordinárias", é outra ferramenta utilizada nos estudos sobre mulheres. E, por fim, sua análise dos poderes, onde aborda questões como os micropoderes, disciplina e subjetividade.

Nada melhor para ilustrar essas possibilidades de contribuições do que citar, mais uma vez, um fragmento do pensamento deste autor.

\begin{abstract}
(...) em toda a sociedade a produção do discurso é ao mesmo tempo controlada, selecionada, organizada $e$ redistribuída por certo número de procedimentos que têm por função conjurar seus poderes e perigos, dominar seu acontecimento aleatório, esquivar sua pesada e temível materialidade (Foucault, 2005:8, 9).
\end{abstract}

Fragmento este que nos remete ao fato de a história das mulheres encontrar-se à margem da história oficial, daquela que se quer contar.

\title{
O lugar dos "lugares de memória"
}

Diante de tantas "armadilhas" colocadas pelas disputas discursivas, desencadeando silêncios, ausências, desigualdades, talvez seja interessante pensar na função que os lugares de memória podem desempenhar neste cenário.

"Lugar de memória" é um termo explorado e discutido pelo historiador Pierre Nora. De acordo com seu pensamento, os lugares de memória fazem-se necessários por não haver mais meios de memória, ou seja: "se habitássemos ainda nossa memória, não teríamos necessidade de lhe consagrar lugares" (Nora, 1993:8). Nora acredita que a memória não encontra 
alternativas, atualmente, para escapar dos procedimentos históricos, sendo, assim capturada e, conseqüentemente, "destruída" pela história. Essa historicização da memória faz com que para a memória restem, apenas, lugares de memória. Nesse sentido, para Nora, os lugares de memória são espaços criados pelo indivíduo contemporâneo diante da crise dos paradigmas modernos, e que com esses espaços se identificam, se unificam $e$ se reconhecem agentes de seu tempo (Arévalo, 2004).

Seixas não concorda quando Nora diz que os lugares de memória existem devido ao fato de não habitarmos mais a nossa memória, argumentando que esses lugares estariam relacionados a

(...) irrupções afetivas e simbólicas da memória em seu diálogo sempre atual com a história. É porque habitamos ainda nossa memória, (...) que lhe consagramos lugares, cada vez mais numerosos e, freqüentemente, inusitados (ao menos ao olhar sempre armado da história) (Seixas, 2004:44).

Na carona do dito acima, tomamos a liberdade para falar de lugares de memória como não apenas aqueles consagrados, monumentos históricos, instituídos voluntariamente. Acrescentamos a essa categoria também lugares imprevisíveis, como uma roupa, um diário, uma revista, um filme, ou, como sugere Marcel Proust, um odor e, até mesmo, a combinação do gosto de um pedaço de bolo com chá.

Esses "lugares" de memória podem falar muito. Podem ser únicos e proporcionarem memórias também únicas. Podem trazer importantes revelações, assim como suscitar as mais variadas $e$ enriquecedoras lembranças. Esta foi a experiência vivenciada durante a entrevista com leitoras da Capricho, que viveram sua juventude em 1950 e 1960 e que, no momento da entrevista, tinham em mãos exemplares de época da revista. 
A revista Capricho fez e faz parte da juventude de grande parte das jovens de diferentes épocas. Izaura, Irene e Lídia (as três leitoras entrevistadas) são representantes de uma geração que tinha a leitura de exemplares da Capricho como hábito, paixão e diversão.

Durante a entrevista - ou melhor, bate-papo - com essas três mulheres, presenciei diversos momentos em que a revista serviu como estopim, trazendo à tona lembranças de uma história vivida. Alguns pontos, em especial, parecem ter saltado aos olhos destas mulheres ao re-visitarem as páginas da Capricho. Assim que disponibilizei os oito exemplares da revista às minhas interlocutoras, Irene, ao olhar sua capa, disse: "Ai os cabelos, ó... Eu usei muito, Raquel! Sabe o que que é isso aqui [apontando para o cabelo da moça da capa]? Bombril. É, Raquel, botava, Raquel!".

Comentários sobre atores, principalmente norte-americanos como Tony Perkins, Rock Hudson, também foram feitos. Lídia, Izaura e Irene falaram da decepção que tiveram ao descobrir que Rock Hudson era homossexual. Lídia traz a seguinte lembrança:

L- Aí eu lembro que ele [um amigo] chegava e dizia: "Vamos jogar no cavalo?" Eu dizia: "Ai, hoje no cavalo não, eu quero ir no cinema". E ele "Você vai deixar de jogar para ir no cinema?" Eu falava: "Eu quero ver aquela coisa linda [Rock Hudson]." Pena que eu não tenho mais contato com ele, senão ele ia dizer: "Viu, ele era bicha!"

Além de sua paixão pelos contos presentes na Capricho, Irene revela outra seção que lhe despertava interesse:

Ir- Agora eu gostava mesmo, Raquel, era disso aqui [mostra para mim a página que estava vendo]: fotonovela.

L- O que eu gostava mais era fotonovela, fofoquinhas. Ah, e contos também são bons.

Ir- Não, eu fotonovela e contos. Coisa que eu mais gostava. Ai!, tinha cada homem lindo! 
Estas falas demonstram a relação que estas mulheres têm com o tempo. Fica clara a percepção destas leitoras a respeito de que o que aconteceu é diferente dos tempos de hoje, a sensação do tempo que passou, o que mudou.

Entretanto, ao longo da entrevista, nada foi mais comentado pelas leitoras do que as propagandas ${ }^{8}$ exibidas nas páginas da Capricho. Entre as mais citadas e comentadas por elas estão: roupa de banho (maiô), produtos Cashmere Bouquet, Antisardina, creme C Ponds, Sonrisal, Melhoral, soutien Darling, Leite de Colônia e Leite de Rosas, Maizena, Gessy Léver, desodorante, Leite moça, Modess, sardinhas Coqueiro, pó Royal. Os comentários sobre os anúncios, geralmente, suscitavam um encadeamento de lembranças e histórias.

Dessa forma é possível pensar na possibilidade que os anúncios abrem para a análise dos papéis sociais destinados às mulheres de uma determinada época, refletindo sobre a possível participação das propagandas na constituição das subjetividades das mulheres e homens de uma geração. Ou seja, a possibilidade de ter as propagandas como lugares de memória, encarando-as como importante fonte de acesso a silêncios de até então.

Ainda com relação à publicidade, é importante considerar que desde a sua criação ela está implicada em um processo de produção de subjetividades. Mesmo quando alguns publicitários afirmam que não criam, mas sim refletem o social, deve-se considerar que cada pessoa lê de forma diferente as mesmas prescrições normativas. Logo, o que me parece uma leitura óbvia daquilo que o contexto apresenta talvez não seja compartilhado por outra pessoa. Dessa forma, não existe uma única leitura, não

\footnotetext{
8 Lançaremos mão de utilizar tanto o termo propaganda, quanto anúncio, apresentando-os, aqui, como sinônimos. Cabe ressaltar a distinção, destacada por diversos autores, entre o que vem a ser propaganda e publicidade. Segundo Widholzer (2005), por exemplo, publicidade está associada à venda de produtos, enquanto propaganda está voltada à divulgação de idéias, sejam elas políticas, ideológicas ou eleitorais.
} 
é possível falar em "refletir" algo. Assim, não se pode deixar escapar a noção da subjetividade vista

pelo ângulo de sua produção por instâncias individuais, coletivas $e$ institucionais [procurando assim] apreender a subjetividade em sua dimensão de criatividade processual, como todo um conjunto de circunstâncias histórico-sócioculturais e biográficas que enseja o sentido do eu (Matos, 2005:28).

Além das propagandas de Cashemere Bouquet e Modess, acrescento o relato de Irene ao se deparar com um anúncio do soutien Darling.

Ir - Olha o soutien Darling, gente, meu primeiro soutien foi Darling.

$\mathrm{R}$ - Quem que te deu, Irene?

Ir - A minha madrinha. Eu não usava soutien porque eu não tinha nada, né, eu tinha dois ovinhos fritos. Aí, mas eu fiquei tão boba de por, eu só tinha ele. O meu segundo soutien eu comprei quando eu casei, porque eu, eu só, imagina Raquel, eu não tinha nada. Então, era rosa, todo rendado, uma coisa linda. Mas eu levei só pro Altair [marido de Irene], pois como é que eu vou casar, viajar pra lua de mel sem soutien! Comprei só pra dizer que eu tinha, que eu usava! Mas eu não, eu detestava, detesto, até hoje, né, eu não gosto de usar. Então eu comprei pra fazer número, só. Meu primeiro soutien rosa, a coisa mais linda! Darling, darling [fala apontando para a propaganda na revista].

Esses relatos acabam por demonstrar a maneira como essas propagandas atuaram como verdadeiros "lugares de memória" para as três leitoras. Certamente, os anúncios citados encontramse em consonância tanto com o conteúdo da Capricho, quanto com o discurso predominante no momento.

Em especial no final dos anos 1950 e início dos anos 1960, 
no ritmo do final da II Guerra Mundial, enfatizam-se os ideais de domesticidade e dependência das mulheres, uma vez que elas precisavam deixar os postos de trabalho e retornarem ao lar. $\mathrm{O}$ mundo das mulheres fora reduzido, então, às paredes de sua casa. Betty Friedan (1971) ao discutir a mística feminina, tendo como universo mulheres estadunidenses e de camadas médias, destaca a forte atuação das revistas femininas frente à ênfase na importância da permanência das mulheres no lar. Grande parte das revistas voltada às mulheres limitava-se a abordar, em suas páginas, assuntos relacionados ao universo doméstico.

Ao longo de suas reflexões, Friedan se questiona:

Não faz muito as mulheres sonhavam e lutavam pela igualdade, por seu lugar ao sol. Que acontecera aos seus sonhos? Quando decidiram renunciar ao mundo e voltar ao lar? (Friedan, 1971:35).

Junto a isso, está presente a ênfase no moderno, no novo: salientam-se as qualidades do novo em detrimento do velho, dos produtos tidos como do "tempo da vovó" (Sant`Anna, 1997), estratégia utilizada pelos anúncios de Modess presentes nas edições da Capricho da época aqui analisada. Aliás, lança-se mão desse recurso ainda atualmente.

Percebe-se, dessa forma, o quanto os anúncios estavam a serviço da manutenção $e$ da construção de certos hábitos $e$ atitudes que estavam relacionados ao ideal de mulher apregoado na época. Vale ressaltar que entre os novos hábitos e atitudes encontra lugar a mulher vista como consumidora. Através de seus textos e suas imagens, as propagandas encantaram e envolveram mulheres, conquistando consumidoras que associam os produtos a experiências íntimas por elas vividas.

Como um lugar de memória, ressaltamos a "viagem no tempo" que a Capricho proporcionou a suas leitoras. Durante as entrevistas percebemos o quanto o fato de ter manuseado aquelas revistas fez com que se criasse um clima, ou melhor, com que se 
re-criassem cenários, se re-vivessem emoções. É claro que esse passado vem pelos olhos do presente, é por ele reconstruído, passa por reformulações, ganha colorido...

Nesse sentido, mesmo quando não era citada uma passagem específica - uma propaganda, um conto, uma fofoca ou uma fotonovela -, a revista atuou como lugar de memória pelo simples fato de proporcionar uma viagem a tempos de outrora. Segundo Izaura, ter passeado pelas páginas daquelas revistas lhe trouxe uma série de lembranças: sobre namoro, noivado, escola, o quanto era "boba e tímida", a casa onde morou, lhe fez lembrar do quanto sonha ainda hoje com a casa em que morou enquanto era casada, o quanto sonha com seu ex-marido... "Essas coisas que estão muito enraizadas na gente", disse ela.

O espectro de lembranças trazido pelas leitoras da Capricho, proporcionou-nos perceber a diversidade de possibilidades na constituição das subjetividades, mesmo em uma mesma época, em uma mesma camada social, em um mesmo universo de leitura e de produtos a serem consumidos. É como um caleidoscópio: mesmas peças formando as mais diversas figuras, através de um simples movimento, construindo as várias histórias das mulheres.

\section{Referências bibliográficas}

ARÉVAlO, Márcia Conceição da Massena. Lugares de memória ou a prática de preservar o invisível através do concreto, 2004. http://www.anpuh.uepg.br/historia-hoje/vol3n7/marcia.htm [em 04/03/2006].

Bassanezi, Carla. Mulheres dos Anos Dourados. In: Del PRiore, Mary. (org.) História das mulheres no Brasil. São Paulo, Contexto, 2001.

BENJAMIN, Walter. Charles Baudelaire: um lírico no auge do capitalismo. Obras escolhidas - Vol. III. São Paulo, Brasiliense, 1995.

BOSI, Ecléa. Memória e sociedade: lembranças de velhos. São Paulo, T.A. Queiroz/Editora da USP, 1987. 
DEL PRIORI, Mary. História das mulheres: as vozes do silêncio. In: FREITAS, Marcos Cezar de. (org.) Historiografia brasileira em perspectiva. São Paulo, Contexto, 1998.

FoucAult, Michel. História da sexualidade: a vontade de saber. Rio de Janeiro, Graal, 1997.

. A ordem do discurso. São Paulo, Edições Loyola, 2005.

Friedman, Betty. A mística feminina. Petrópolis, Editora Vozes, 1971.

GAGneBIN, Jeanne Marie. História e narração em Walter Benjamin. São Paulo, Perspectiva, 1999.

GuATARRI, Félix; ROLNIK, Suely. Micropolítica: cartografias do desejo. Petrópolis, Vozes, 1986.

HalbWACHS, Maurice. A memória coletiva. São Paulo, Centauro, 2004.

LANZARIN, Cláudia Cruz. A fantasia e o baile de máscaras do final do milênio. Psicologia: ciência e profissão (20)3, 2000, pp.28-33.

LE Goff, Jacques. História e memória. Campinas-SP, Editora da UNICAMP, 2003.

MALUF, Marina. Ruídos da memória. São Paulo, Siciliano, 1995.

MATOS, Maria Izilda Santos de. Âncora de emoções: corpos, subjetividades e sensibilidades. Bauru, EDUSC, 2005.

Miguel, Raquel de Barros Pinto. A revista Capricho como um "lugar de memória" (décadas de 1950 e 1960). Tese de doutorado, Ciências Humanas, UFSC, 2009.

NORA, Pierre. Entre memória e história: a problemática dos lugares. Projeto história (10), São Paulo, Editora da PUC-SP, dezembro de 1993, pp.7-29.

OrlandI, Eni Puccinelli. As formas do silêncio: no movimento dos sentidos. Campinas, Editora da UNICAMP, 1995.

PERROT, Michelle. As mulheres ou os silêncios da história. Bauru, EDUSC, 2005. 
PORTELLI, Alessandro. A filosofia e os fatos: narração, interpretação $e$ significado nas memórias e nas fontes orais. Tempo (1)2, Rio de Janeiro, Editora Relume Dumará, 1996, pp.59-72.

. Tentando aprender um pouquinho: algumas reflexões sobre a ética na História oral. Projeto história (15), São Paulo, Editora da PUC-SP, abril de 1997, pp.13-49.

SALVATICI, Silvia. Memórias de gênero: reflexões sobre a história oral de mulheres. História oral (8)1, Rio de Janeiro, Editora da FGV, 2005, pp.29-42.

SANT'AnNA, Denise Bernuzzi de. Propaganda e História: antigos problemas, novas questões. Projeto história (14), São Paulo, Editora da PUC-SP, abril de 1997, pp.89-112.

SCOTT, Joan. Gênero: uma categoria útil de análise histórica. Educação e realidade 20(2), 1995, pp.71-99.

SEIXAS, Jacy Alves. Percursos da memória em terras de história: problemáticas atuais. In: BRESCIANI, Stella e NAXARA, Márcia. (orgs.) Memória e (res)sentimento: indagações sobre um questão sensível. Campinas-SP, Editora da UNICAMP, 2004, pp.37-58.

SIQUEIRA, Maria Juracy Toneli. A construção da identidade masculina: alguns pontos para discussão. Psicologia USP 8(1), 1997, pp.113-130

VeYNE, Paul. Acreditavam os deuses em seus mitos? Lisboa, Edições 70, 1987.

WIDHOLZER, Nara. A publicidade como pedagogia cultural e tecnologia de gênero: abordagem lingüístico-discursiva. In: FUNCK, Susana Bornéo e WiDHOLzer, N. R. Gênero em discursos da mídia. Florianópolis/Santa Cruz do Sul, Editora Mulheres/Edunisc, 2005, pp.17-52. 